\title{
Lymphocyte destruction by antibody-dependent cellular cytotoxicity mediated in vitro by antibodies in serum from patients with systemic lupus erythematosus
}

\author{
MAREN L. MAHOWALD AND AGUSTIN P. DALMASSO \\ From the Departments of Medicine and of Laboratory Medicine and Pathology, University of Minnesota \\ Medical School and the Minneapolis VA Medical Center, Minneapolis, USA
}

SUMMARY Sera from patients with systemic lupus erythematosus (SLE) were tested for the presence of IgG antilymphocyte antibodies that are capable of mediating antibody-dependent cellular cytotoxicity (ADCC) of peripheral blood lymphocytes (PBL) from normal donors. The effector cells employed were PBL autologous with the target PBL. Positive ADCC responses were obtained with serum from 5 SLE patients with severe active disease. It is possible that ADCC is a mechanism by which IgG antilymphocyte antibodies in patients with SLE may mediate in-vivo lymphocytolysis.

Antilymphocyte antibodies (ALA) occur spontaneously as autoantibodies in many patients with rheumatic diseases and are most frequently found in patients with systemic lupus erythematosus (SLE). ${ }^{1-6}$ They may also appear after alloimmunisation by multiple pregnancies, multiple blood transfusions, and organ transplantation and with certain infections. ${ }^{37-9}$ Although certain properties of these antibodies have been established, their pathogenetic significance remains unclear.

ALA are usually detected by complement lysis in a microcytotoxicity test, ${ }^{3}$ indirect immunofluorescence, ${ }^{10-12}$ inhibition of certain immune functions such as response to allogeneic stimulation and phytohaemmagglutinin, ${ }^{13}{ }^{14}$ inhibition of generation of suppressor cell activity by concanavalin $\mathrm{A},{ }^{15-17}$ and by binding of ${ }^{125}$ I-protein $A .{ }^{18}$ The microcytotoxicity test depends on antibody binding at low temperature followed by complement activation to damage the target cell. Most of these antibodies are IgM with increased reactivity at cold temperatures. The antibodies which interfere with lymphocyte functions are found in both the IgG and IgM classes and react optimally at $37^{\circ} \mathrm{C}$. Immunofluorescent studies have also demonstrated both IgG and IgM ALA. A higher incidence of warm reactive IgG ALA was found by preventing capping and shedding of antibody, as previously described. ${ }^{6}{ }^{125} \mathrm{I}$-labelled protein $\mathrm{A}$ detects

Accepted for publication 16 October 1981.

Correspondence to Dr Maren L. Mahowald, Rheumatology Section, Minneapolis VA Medical Center, 54th Street \& 48th Avenue S, Minneapolis, MN 55417, USA.
ALA in patients with active SLE by combining to the Fc portion of lymphocyte-bound IgG. ${ }^{18}$

One potential mechanism for lymphocyte damage produced by ALA which has not been extensively studied is antibody-dependent cellular cytotoxicity (ADCC). ADCC is a cytolytic process in which target cells generally coated with an IgG antibody are lysed by nonimmune killer cells. The Fab fragment of the antibody reacts specifically with the target cell and the Fc fragment attaches to the Fc receptor of the effector killer cell. ${ }^{1920}$ Since this mechanism reacts optimally at $37^{\circ} \mathrm{C}$, it could be operative in vivo. Therefore, since $\mathrm{IgG}$ is the principal antibody which mediates ADCC, and SLE patients have IgG ALA, we propose that this mechanism might produce selfdestruction of peripheral blood lymphocytes in vivo.

\section{Materials and methods}

PREPARATION OF PERIPHERAL BLOOD LYMPHOCYTES (PBL)

Heparinised human venous blood was diluted 1:2 with phosphate buffered saline (PBS), layered over Ficoll-Hypaque, and centrifuged at $600 \mathrm{~g}$ for 40 minutes at room temperature. ${ }^{21}$ The interface layer of PBL was removed and washed twice with Roswell Park Memorial Institute (RPMI) 1640 medium (Gibco) supplemented with $10 \%$ fetal calf serum, penicillin, streptomycin, and glutamine (medium). For target cells $20 \times 10^{6} \mathrm{PBL}$ were mixed with 150 $\mu \mathrm{Ci} \mathrm{Na}{ }^{51} \mathrm{CrO}_{4}$ (New England Nuclear, NEZ 030, $200-500 \mathrm{Ci} / \mathrm{g}$ ) at $37^{\circ} \mathrm{C}$ for one hour and washed twice with medium. The remaining PBL were kept at room 
temperature until used as effector cells. Aggregated IgG was prepared according to a published procedure $^{22}$ and used at $5-10 \mathrm{mg} / \mathrm{ml}$ for incubation with effector cells (vide infra).

\section{PREPARATION OF SERUM}

Blood was allowed to clot at room temperature and the serum was separated by centrifugation, incubated at $56^{\circ} \mathrm{C}$ for one hour to inactive complement, and stored in aliquots at $-40^{\circ} \mathrm{C}$ until used. To obtain the IgG fraction, serum was subjected to diethylaminoethyl (DEAE) cellulose chromatography with $0 \cdot 01 \mathrm{M}$ sodium phosphate buffer, $\mathrm{pH} 7 \cdot 3$. To prepare the IgM fraction serum was chromatographed on Sephadex G-200 (Pharmacia) employing

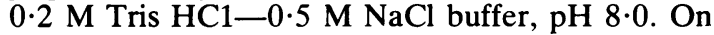
analysis by double immunodiffusion the $\mathrm{IgG}$ fraction contained no $\operatorname{IgM}$ or $\operatorname{IgA}$, and the $\operatorname{IgM}$ fraction was free of IgG and IgA. Rabbit antihuman lymphocyte antiserum ( $\mathrm{RaALA}$ ) was produced by immunisation with 4-6 weekly intravenous injections of about $10^{8}$ PBL from different normal donors.

\section{ADCC ASSAY}

This assay was based on methods used to detect ALA in serum from multiply transfused patients. ${ }^{23}$ Labelled target cells $\left(1 \times 10^{4}\right)$ were placed in $12 \times 75$ polystyrene tubes (Falcon 2054) and incubated with dilutions of patient and control serum for 30 minutes at $37^{\circ} \mathrm{C}$ and 30 minutes at $20^{\circ} \mathrm{C}$ to permit antibody coating. The cells were then washed with 20 volumes of medium to remove excess serum which could contain immune complexes or antieffector cell ALA. ${ }^{24}$ Effector cells were added to give target-effector cell ratios of $1: 50$ to $1: 100$ in a final volume of $0.2 \mathrm{ml}$. The reaction mixture was placed on a slowly rocking platform in a humidified incubator with $5 \% \mathrm{CO}_{2}$ for 1.5 hours at $37^{\circ} \mathrm{C}$. After addition of $0.8 \mathrm{ml}$ of ice-cold PBS the tubes were centrifuged at $700 \mathrm{~g}$ for 10 minutes, and $0.5 \mathrm{ml}$ of the supernatant fluid was removed. The radioactivity in the supernatant fluid and in the sedimented cells was measured in a gamma counter. Samples were prepared in triplicate and the data reported as the mean percentage lysis ( \pm standard deviation), which was calculated as follows:

$$
\% \text { lysis }=\frac{\text { counts in supernatant fluid }}{\text { total counts }} \times 100 \text {. }
$$

Total counts comprised the sum of 'pellet' and 'supernatant' counts. 'Spontaneous release' of ${ }^{51} \mathrm{Cr}$ from target cells was determined by measuring the counts in the supernatant fluid from a mixture of effector and target cells without antibody. Release of ${ }^{51} \mathrm{Cr}$ from target cells alone, and target cells with antibody, was monitored in each experiment. Specific lysis (SL) was calculated by subtracting the mean percentage spontaneous release from the mean percentage experimental release in tubes with antibody-coated target cells and effector cells. The low levels of spontaneous ${ }^{51} \mathrm{Cr}$ release demonstrated the antibody dependence of this assay. The cellular dependency of the assay was demonstrated by lack of lysis in tubes containing antibody-coated ${ }^{51} \mathrm{Cr}$ labelled target cells but no effector cells. Each human serum (1/10 dilution) was tested with targets and effectors from 3 to 5 normal donors with different HLA phenotypes.

As has been recently reported with the chicken erythrocyte-ADCC assay, ${ }^{25}$ this PBL-ADCC assay with human and rabbit ALA is readily reproducible from day to day with the same PBL donor but is quite variable from donor to donor. ADCC specific lysis of human PBL targets from many different normal donors in the presence of RaALA (1/640 dilution) ranged from $8 \%$ to $37 \%$ (mean $19.5 \%$ ). Therefore, in order to compare the results from testing an individual patient's serum in different experiments we converted specific lysis to a cytotoxicity index $\left(\mathrm{CI}^{26}\right)$. The $\mathrm{CI}$ expresses the mean specific lysis produced by the patient's serum relative to the positive serum control with RaALA for that experiment. CI was calculated according to the following formula:

$$
\mathrm{CI}=\frac{\text { specific lysis with patient serum }}{\text { specific lysis with RaALA }} \times 100 .
$$

\section{Results}

CHARACTERISTICS OF THE ADCC ASSAY

The time course of this assay is illustrated in Fig. 1. ADCC lysis is detectable within $30 \mathrm{~min}$ and increases rapidly over the next hour. From $2 \cdot 5$ to 20 hours lysis roughly parallels the spontaneous release. Therefore the time of incubation that was selected for all studies was 1.5 hours.

In preliminary experiments different effector-totarget cell ratios (E/T) were tested. ADCC specific lysis increased linearly with increasing $E / T$ ratios of $1: 1,10: 1,20: 1$, and 50:1 (data not given). Increasing the $E / T$ ratio from $50: 1$ to $100: 1$ produced only a $2-4 \%$ increase in ADCC-SL. Therefore we used an effector cell/target cell ratio of 50:1 when testing patient sera for ALA.

\section{CONTROLS}

A positive control with RaALA was performed for each experiment. A preliminary study with this antibody showed that it reacted with PBL from all 15 normal donors tested. In a total of 55 experiments RaALA produced ADCC specific lysis of $19.5 \% \pm$ $7 \cdot 5 \%$ (mean \pm SD) with a range of $8-37 \%$. The negative serum control for each experiment was a 


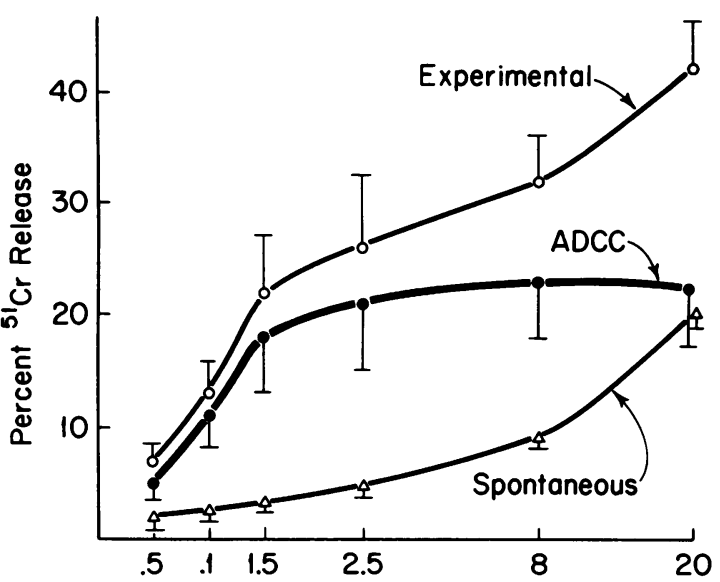

Hours of Incubation

Fig. 1 Time course of the ADCC Assay. Results at different time points represent values from 3 experiments performed on the same day with $P B L$ from different donors.

Experimental release ( ${ }^{\circ}$ ) of ${ }^{51} \mathrm{Cr}$ from tubes containing targets, 1/320 RaALA, and effectors. Spontaneous release $(\triangle)$ of ${ }^{51} \mathrm{Cr}$ from tubes containing targets, medium, and effectors. ADCC specific lysis $(\bullet)$ is experimental release minus spontaneous release. Vertical lines represent one standard error of the mean. Note parallel increase in experimental and spontaneous release after $2.5 \mathrm{~h}$ incubation so that calculated ADCC-SL does not increase with extended periods of incubation.

$1 / 10$ dilution of pooled normal human serum (NHS) (Gibco, lot 200-6252). In 55 determinations specific lysis for NHS was $0.7 \% \pm 0.9 \%$ (range of 0 to $2 \cdot 4 \%$ ), and the cytotoxicity index was $5 \cdot 2 \pm 7 \cdot 5 \%$. When patient sera were tested, a CI of $21 \%$ or greater (mean of negative controls $+2 \mathrm{SD}$ ) was designated as positive for ALA mediating ADCC.

Before sera from patients with SLE were studied, it was important to be certain that this ADCC assay could be mediated by human ALA. Therefore an experiment was performed with serum from a patient who received more than 50 blood transfusions because of chronic anaemia. This serum was positive in ADCC to a 1/640 dilution. The ADCC reaction was mediated by the IgG but not by the IgM fraction. When this serum was reacted with PBL from several donors, ADCC-CI ranged from 26 to $117 \%$. These studies showed that the ADCC assay was mediated by human ALA. Comparative titrations of human and rabbit ALA showed that this human ALA usually induced less target cell lysis than the rabbit ALA (Fig. 2).

An effector cell negative control was included in all experiments. To verify that ADCC was the operative mechanism causing lysis of antibody-coated target lymphocytes, effector cell $\mathrm{Fc}$ receptors were blocked by incubating effector cells with $5-10 \mathrm{mg} / \mathrm{ml}$ heataggregated $\mathrm{IgG}^{22}$ for one hour at room temperature before mixing with the target cells. In 22 determinations this treatment of effector cells inhibited ADCC of RaALA coated target cells by a mean of $75 \%$. A similar degree of inhibition also occurred with human ALA-mediated ADCC.

\section{PATIENT STUDIES}

Ninety-four serum samples from 51 patients with LE were tested for ALA in the ADCC assay with PBL from 4-6 normal donors with different HLA phenotypes. Thirteen samples were positive with CI ranging from 22 to $115 \%$ (Table 1 ). The positive sera were obtained from 5 female LE patients who had severe multisystem disease and were being treated with prednisolone and/or cytotoxic therapy. As indicated in Table 1 , sera 2,4 , and 5 were positive with PBL from all donors tested, and sera 1 and 3 induced ADCC of PBL from 3 of 6 and 3 of 4 donors respectively. The mean ( \pm SD) ADCC-CI for all SLE sera was $12 \cdot 8 \% \pm 1 \cdot 9 \%$. The mean ADCC-CI for positive sera was $57 \% \pm 7 \cdot 6$. For the remaining negative sera the mean $\mathrm{CI}$ was $6 \cdot 3 \% \pm 0 \cdot 8$, which is similar to the CI of $5.5 \%$ obtained with NHS, the negative serum control. Four of the positive LE sera and the $\mathrm{RaALA}$ were separated into IgG and IgM fractions. These fractions were tested in the ADCC Assay

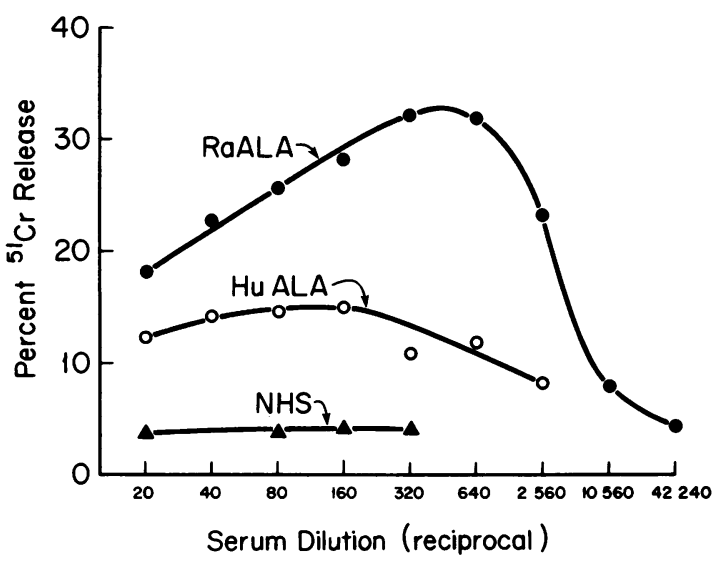

Fig. 2 Comparative titrations of rabbit antilymphocyte antibody (RaALA) and human antilymphocyte antibody (HuALA) in the ADCC Assay. Peripheral blood lymphocytes from a normal donor were used as target and effector cells (see 'Materials and methods' for further details). Note that RaALA produced higher percentage lysis than the $H u A L A$. Incubation time was 90 min at $37^{\circ} \mathrm{C}$, with effector/target ratio of 50/1. 
Table 1 Antibody-dependent cellular cytotoxicity induced by serum from patients with SLE

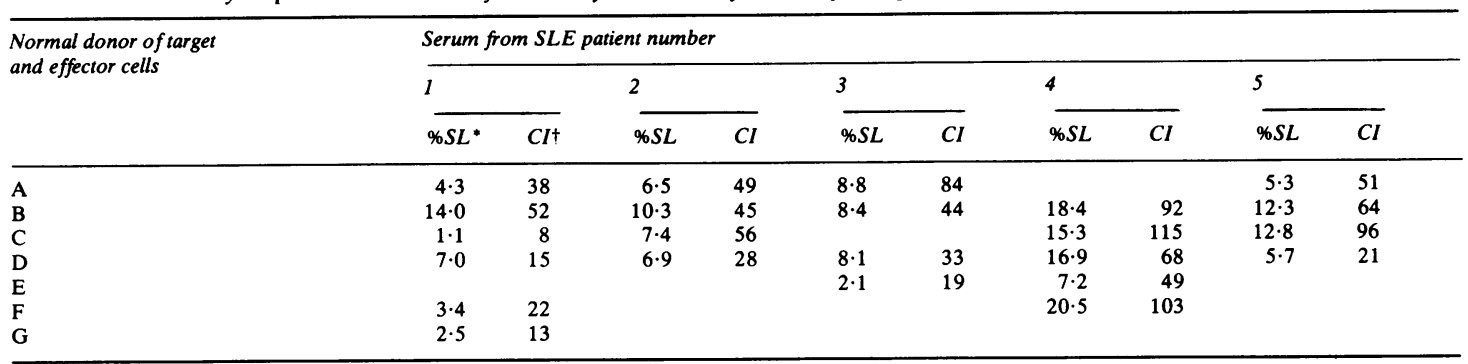

*SL, Specific lysis=experimental percentage lysis minus spontaneous percentage lysis.

$+\mathrm{CI}$, cytotoxicity index $=\frac{\text { SL with patient ALA }}{\text { SL with rabbit ALA }} \times 100$.

(Table 2). The ADCC activity was present in the IgG but not the IgM fractions. The ADCC activity mediated by whole serum and the IgG fractions was inhibited $50-75 \%$ by the pretreatment of effector cells with $6 \mathrm{mg} / \mathrm{ml}$ heat-aggregated IgG. Four of the 94 SLE serum samples tested appeared to be toxic to the ${ }^{51} \mathrm{Cr}$-release. Pretreatment of effectors with aggregates did not inhibit ${ }^{51} \mathrm{Cr}$-release from the target cells during the ADCC reaction, showing that these toxic sera produced false positive results.

Table 2 ADCC specific lysis with IgG and IgM fractions of LE $A L A$ and inhibition by aggregated $\operatorname{IgG}$

\begin{tabular}{|c|c|c|}
\hline Serum & $A D C C S L^{*}$ & $\operatorname{Agg} A D C C S L \dagger$ \\
\hline RaALA whole & $18 \cdot 7$ & $2 \cdot 9$ \\
\hline IgG $\ddagger$ & $26 \cdot 1$ & $6 \cdot 4$ \\
\hline IgM & $2 \cdot 9$ & $0 \cdot 8$ \\
\hline $\mathrm{LE}_{4}$ whole & $7 \cdot 3$ & $3 \cdot 7$ \\
\hline IgG & $6 \cdot 4$ & $3 \cdot 5$ \\
\hline IgM & 0 & 0 \\
\hline $\mathrm{LE}_{1}$ whole & $12 \cdot 0$ & $2 \cdot 1$ \\
\hline IgG & $5 \cdot 7$ & $0 \cdot 7$ \\
\hline IgM & $1 \cdot 3$ & $1 \cdot 1$ \\
\hline $\mathrm{LE}_{2}$ whole & $7 \cdot 1$ & 0.9 \\
\hline IgG & $6 \cdot 3$ & $1 \cdot 4$ \\
\hline IgM & $1 \cdot 1$ & 0 \\
\hline LEs whole & $12 \cdot 3$ & ND\& \\
\hline IgG & $7 \cdot 9$ & $2 \cdot 2$ \\
\hline IgM & 0.5 & $1 \cdot 1$ \\
\hline
\end{tabular}

*ADCC SL= percentage specific lysis (experimental-spontaneous release) in ADCC assay.

†Agg ADCC SL=percentage lysis in ADCC assay inwhich effectors were preincubated with $5 \mathrm{mg} / \mathrm{ml}$ heat-aggregated $\mathrm{IgG}$ for $1 \mathrm{~h}, 37^{\circ} \mathrm{C}$, before mixing with antibody coated targets. Spontaneous release was less than $4 \%$. Time of incubation was $90 \mathrm{~min}$ at ${ }^{\circ} \mathrm{C}$. Effector/target ratio: $50 / 1$.

$\ddagger \mathrm{IgG}$ and IgM fractions were prepared as described in 'Materials and methods.' $\S \mathrm{ND}=$ not done.

\section{Discussion}

The occurrence of ALA and lymphocytopenia has been described in patients with SLE. ${ }^{6}$ In these studies ALA were detected primarily by complementdependent cytotoxicity assays, and it has been assumed that this is also the in-vivo mechanism of lymphocytolysis. Kumagai et al. ${ }^{27}$ have recently reported that IgG ALA from 8 patients with SLE mediated ADCC against T lymphocytes. The results of our study confirm that IgG ALA can mediate lymphocytolysis by ADCC. The ADCC mediating ALA is a warm-reactive IgG antibody, which suggests that ADCC might be an in-vivo lymphocytolytic mechanism in patients who produce these antibodies. The ALA reactive in this assay were obtained from 5 patients who had severe multisystem disease and required prednisone or cytotoxic therapy. By using several target cell donors to test the sera we observed that the reactivity was not restricted to an individual HLA phenotype but occurred with PBL from unrelated donors of different HLA phenotypes. Therefore it is unlikely that ALA from these patients were the result of pregnancy-induced alloimmunisation. This ADCC assay has several features not present in other methods commonly used to study human ALA. The complement-dependent microcytotoxicity assay detects primarily IgM ALA and not IgG ALA because of a limited capacity of low concentrations of IgG to activate complement. ${ }^{28}$ In spite of the relatively low level of specific lysis produced by ALAmediated ADCC, the consistently low levels of spontaneous ${ }^{51} \mathrm{Cr}$ release in the absence of ALA, together with the ability to inhibit the reaction with aggregated IgG, permit use of this assay to study lymphocytolysis mediated by human IgG ALA. ${ }^{29}$

ADCC with rabbit ALA consistently produced greater lysis of PBL target cells than the human 
ALA. This relatively low level of lysis was also found in other studies of ADCC with human ALA. ${ }^{782023}$ The rabbit antiserum may have a higher concentration of immune ALA or may contain naturally occurring additional $\mathrm{ALA}^{22}{ }^{28}$ which could augment the ADCC. These naturally occurring rabbit ALA are thought to play an important role in enhancing the complement-dependent microcytotoxicity tests used to detect cold reactive human IgM ALA. ${ }^{30}$

ADCC inducing ALA from patients with LE may react with only a $\mathrm{PBL}$ subpopulation, whereas all PBL appear to react with rabbit ALA. Other investigators have reported restricted specificity of SLE ALA for certain lymphocyte subpopulations. ${ }^{46}$ For example, it has been shown that some SLE ALA react with a subset of suppressor $T$ cells. ${ }^{15-17}$ The mechanism by which these ALA coated cells are eliminated or their function impaired has not been clearly defined. It has also been reported that after incubation with sera from a patient with SLE there is loss of $\mathrm{T}$ cells in one of the fractions obtained by discontinuous Ficoll gradient centrifugation. ${ }^{31}$ The loss of these cells was minimised by the addition of aggregated IgG, suggesting that autologous $\mathrm{ADCC}$, produced by ALA, might have been responsible for the decrease in the $T$ cell subpopulation. Our study supports this suggestion and directly demonstrates PBL cytolysis by ADCC induced by sera from some patients with SLE.

Another possible explanation for the low levels of specific lysis of PBL in our study is that the IgG ALA might be of low avidity or might be capped and shed from the PBL target cell surface during the ADCC reaction. This could result in decreased target cell lysis or autoinhibition by the shed immune complexes reacting with $\mathrm{Fc}$ receptors of the effector cells. It is also possible that the standard ADCC assay may not detect all the lymphocyte damage that is produced. This has been shown for ADCC of tumour target cells by mouse spleen effector cells. ${ }^{32}$ Perhaps other methods to detect cell damage, such as incubation of the presumably damaged cells in hypotonic medium, might increase the sensitivity of the ADCC assay. ${ }^{32}$

In the present study the frequency of ADCC mediating ALA in a random collection of stored LE sera was low, only $10 \%$. Therefore ADCC is not useful for screening LE sera for IgG ALA. However, the 5 patients with ADCC mediating IgG ALA had severe multisystem disease. It was impossible to determine the exact state of clinical activity of the disease in all the patients by retrospective review of the charts. It may be that these warm-reactive ALA appear in serum during exacerbation of SLE disease activity. The actual incidence or frequency of ADCC mediating ALA will have to be determined by a prospective study of consecutive SLE patients and correlation with parameters of disease activity.

It remains to be established whether the SLE ALA can produce lymphocytopenia by the mechanism of ADCC in patients with SLE. This possibility is supported by recent evidence that ADCC can be demonstrated with plasma, effector cells, and target cells from patients with SLE. ${ }^{27}$ During exacerbation of SLE, ADCC in a completely autologous system may be difficult to demonstrate, because when the antibody is present in serum, the susceptible PBL population may have been eliminated by ADCC. PBL from patients with active LE may no longer contain the subpopulation of lymphocytes reactive with the ADCC inducing ALA. It may be necessary to obtain serum during active disease and then react it with PBL obtained at a time when the disease is quiescent. The ALA titre may increase in plasma during periods of increased disease activity. Alternatively, they may be present only in patients with severe disease. Longitudinal studies of patients with SLE are being done to determine the actual incidence of ADCC inducing ALA and correlation with disease activity. It also remains to be determined which subsets of lymphocytes are susceptible to ALA in ADCC.

In vitro the ADCC assay system utilises target cell lysis as the measured end point. It is not clear whether this immune mechanism is cytolytic in vivo. It is possible that the interaction of target cell, antibody, and effector cell may have nonlytic functional effects on the target cell which are not detected in the in-vitro cytolytic assay. In vivo the interaction of ALA, lymphocytes, and effector cell may damage and/or alter the functional capacity of the target cell rather than produce lysis. If this were the case, it would then be anticipated that the heterogeneous aspects of ALA specificity apply also to their functional effects. These possibilities await further study.

We thank Drs Ronald Messner and Barry Handwerger for helpful criticism and support during this study, W. E. Smith for expert technical assistance, and Helen Thilmany for typing the manuscript.

This study was supported by grants from the Veterans Administration and the Minnesota Chapter of the Arthritis Foundation.

\section{References}

${ }^{1}$ Stastny P, Ziff M. Antibodies against cell membrane constituents in systemic lupus erythematosus and related diseases. I. Cytotoxic effect of serum from patients with systemic lupus erythematosus (SLE) for allogeneic and for autologous lymphocytes. Clin Exp Immunol 1971; 8: 543-50.

2 Mittal K K, Rosen R D, Sharp J T, et al. Lymphocyte cytotoxic antibodies in systemic lupus erythematosus. Nature 1970; 225: 1255-6.

3 Terasaki P I, Mottironi V D, Barnett E V. Autocytotoxins in lupus. N Engl J Med 1970; 283: 724-7.

4 Lies R B, Messner R P, Williams R C Jr. Relative T-cell specificity of lymphocytotoxins from patients with systemic lupus erythematosus. Arthritis Rheum 1973; 16: 369-75.

5 Butler W T, Sharp J T, Rossen R D, et al. Relationship of the clinical course of systemic lupus erythematosus to the presence 
of circulating lymphocytotoxic antibodies. Arthritis Rheum 1972; 15: 231-8.

${ }^{6}$ Raveche E S, Steinberg A D. Lymphocytes and lymphocyte functions in systemic lupus erythematosus. Semin Hematol 1979; 16: 344-70.

7 Yust I, Wunderlich J R, Mann D L, Terry W D. Identification of lymphocyte dependent antibody in sera from multiply transfused patients. Transplantation 1974; 18: 99-107.

${ }^{8}$ Hewetson J E, Bocker J F, Serini P, Rupp C E, Henle W. Development of antibodies reactive in antibody-dependent cellular cytotoxicity in infectious mononucleosis. Infect Immun 1970; 24: 121-6.

- Pearson G R, Qualtiere L F, Klein G, Norin T, Ball I S. Epstein-Barr virus specific antibody-dependent cellular cytotoxicity in patients with Burkitt's lymphoma. Int J Cancer 1979; 24: 402-6.

${ }^{10}$ Husby G, Messner R P. Detection of antilymphocyte antibodies in patients with systemic lupus erythematosus by indirect immunofluorescence on acetone-fixed lymphocytes. $J$ Lab Clin Med 1977; 89: 240-9.

11 Winfield J B, Winchester R J, Wernet P, Fu S M, Kunkel H G. Nature of cold-reactive antibodies to lymphocyte surface determinants in systemic lupus erythematosus. Arthritis Rheum 1975; 18: 1-8.

12 Messner R P, Kennedy M S, Jelinek J G. Antilymphocyte antibodies in systemic lupus erythematosus. Arthritis Rheum 1975; 18: 201-6.

13 Wernet P, Kunkel H G. Antibodies to a specific surface antigen of T-cells in human sera inhibiting leukocyte culture reactions. $J$ Exp Med 1973; 138: 1021-6.

14 Williams R C Jr, Lies R B, Messner R P. Inhibition of mixed leukocyte culture responses by serum and $\gamma$-globulin fractions from certain patients with connective tissue disorders. Arthritis Rheum 1973; 16: 597-605.

is Sakane T, Steinberg A D, Reeves J P, Green I. Studies of immune functions of patients with systemic lupus erythematosus. Complement-dependent immunoglobulin $M$ anti-thymus-derived cell antibodies preferentially inactivate suppressor cells. J Clin Invest 1979; 63: 954-65.

16 Twomey J J, Laughter A H, Steinberg A D. A serum inhibitor of immune regulation in patients with systemic lupus erythematosus. J Clin Invest 1978; 62: 713-5.

${ }_{17}$ Bresnihan B, Jasin H E. Suppressor function of peripheral blood mononuclear cells in normal individuals and in patients with systemic lupus erythematosus. J Clin Invest 1977; 59: 106-16.

18 Williams R C Jr, Bankhurst A D, Montano J D. IgG antilymphocyte antibodies in SLE detected by ${ }^{125}$ I protein $\mathrm{A}$. Arthritis Rheum 1976; 19: 1261-70.

19 Perlmann P, Perlmann H, Wigzell H. Lymphocyte mediated cytotoxicity in vitro. Introduction and inhibition by humoral antibody and nature of effector cells. Tranplant Rev 1972; 13: 91-114.

${ }^{20}$ Trinchieri G, Demarchi M, Mayr W, Savi M, Ceppellini R. Lymphocyte antibody lymphocytolytic interaction (LALI) with special emphasis on HL-A. Transplant Proc 1973; 5: 1631-46.

${ }^{21}$ Boyum A. Isolation of mononuclear cells and granulocytes from human blood. Isolation of mononuclear cells by one centrifugation, and of granulocytes by combining centrifugation and sedimentation at $1 \mathrm{~g}$. Scand J Clin Lab Invest 1968; suppl 97: 77-89.

${ }^{22}$ Dickler H B, Kunkel H G. Interaction of aggregated $\gamma$-globulin with B lymphocytes. J Exp Med 1972; 136: 191-6.

${ }^{23}$ Connolly J M, Schwartz R H, Handwerger B S, Wunderlich J R. Augmented antibody-dependent cell-mediated cytotoxicity following sensitization or nonspecific stimulation of human effector cells. Transplantation 1975; 20: 186-93.

${ }^{24}$ Zwaifler N J, Bluestein H G. Antibody-mediated suppression of antibody-dependent cytotoxic effector cell function. Clin Immunol Immunopathol 1979; 13: 277-86.

${ }^{25}$ Edwards D L, Avis F P. Antibody-dependent cellular cytotoxicity effector cell capability among normal individuals. $J$ Immunol 1979; 123: 1887-93.

${ }^{26}$ Schocket A L, Kohler P f. Lymphocytotoxic antibodies in systemic lupus erythematosus and clinically related diseases. Arthritis Rheum 1979; 22: 1060-3.

${ }^{27}$ Kumagai S, Steinberg A D, Green I. Antibodies to T cells in patients with systemic lupus erythematosus can induce antibody-dependent cell-mediated cytotoxicity against human $\mathrm{T}$ cells. J Clin Invest 1981; 67: 605-14.

${ }^{28}$ Gershwin M E, Chused T M, Steinberg A D. Cytotoxic activity of anti- $\theta$ antibody found in the $\gamma \mathrm{M}$ fraction. Transplantation 1974; 18: $377-80$.

${ }^{29}$ Stevenson F K, Elliot E V. Mediation of cytotoxic functions by classes and subclasses of sheep antibody reactive with cell surface immunoglobulin idiotypic and constant region determinants. Immunology 1978; 34: 353-8.

${ }^{30}$ Heberman R B. Cytolysis of human cells by antibodies in normal rabbit serum. Transplantation 1969; 8: 813-20.

${ }^{31}$ Glinski W, Gershwin M E, Steinberg A D. Fractionation of cells on a discontinuous ficoll gradient. Study of subpopulations of human $\mathrm{T}$ cells using anti-T-cell antibodies from patients with systemic lupus erythematosus. J Clin Invest 1976; 57: 604-14.

${ }^{32}$ Scornik J C, Klein P A. Antibody-dependent cell-mediated damage of target cells. Transplantation 1978; 26: 356-7. 